\title{
Research on the Effect of Urban and Rural Ecological Economic Development on Labor Transfer based on Ranis-Fei Model
}

\author{
Li Hui \\ Kunming College, Kunming, 650214, China \\ Xuexi123@163.com
}

Keywords: Ranis-Fei, Ecological economy, Generalized coordinates, ANSYS software, Labor.

\begin{abstract}
The development of urban and rural ecological economy mainly depends on the mechanical and other high-tech enterprises, but with the higher requirements on employees, labor transfer problem need to be re evaluated. In order to study the problem of the labor transfer under the new situation, this paper uses mechanical high tech enterprise as an example, combined with the use of UG and ANSYS mechanical design software, and designs Ranis-Fei model of labor transfer, and the model is improved by using the generalized coordinate method. Finally it uses MATLAB toolbox to program algorithm, and the relationship curve surface of surplus labor transfer, high-tech talent demand and the urban/rural labor force transfer in the 3D space is obtained, the dimension reduced processing, improve the visual degree of labor transfer data analysis. It improves the visual degree of labor transfer data analysis and provides the theory reference for the research on the urban and rural ecological economy development.
\end{abstract}

\section{Introduction}

Ranis-Fei is a two element structure model, which studies agricultural and industrial equilibrium growth from the dynamic point and it is improved by John C.H.Fei and Gustav Ranis $\mathrm{g}$ from the Lewis model. They obtained the agricultural surplus is a prerequisite for agricultural labor flowing into the industrial sector $[1,2]$. But along with the development of society, the high-tech occupies an important position in the development process of urban and rural economy, especially the mechanical automation manufacturing industry. The development of machinery industry is mainly influenced by the labor cost and high-tech cost. High-tech depends mainly on high-end simulation design software, so mechanical labor transfer will appear negative feedback phenomenon as shown in Figure 1.

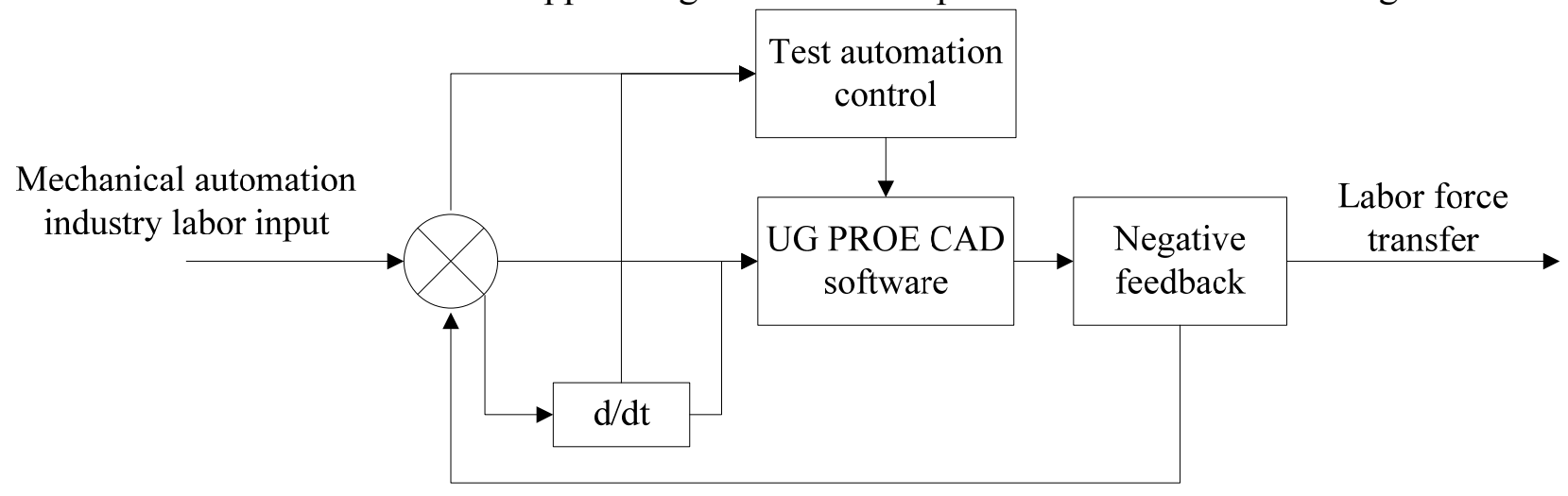

Fig. 1 Labor force transfer negative feedback model of urban and rural machinery enterprises

With the continuous improvement of the automation degree, mechanical design more and more depends on the UG and Proe advanced simulation software [3]. But few people can master this software, which makes the ordinary mechanical working adaptability lower, thus appeared the township workers of urban and rural reflow, which further affects the labor transfer, therefore it needs to update the theory and method of Ranis-Fei model. 


\section{Ranis-Fei Model Theory of Urban and Rural High-tech Economy}

Ranis-Fei model is a two element structure theory studying the balanced growth of agriculture and industry, but with the rapid development of the society and the high technology, the economic development in urban and rural areas is mainly affected by three factors, including residual labor force, high-tech talent demand and urban/rural labor force transfer [4-6]. It can be expressed as shown in formula (1).

$$
J=\left[\begin{array}{l}
a \\
b \\
c
\end{array}\right]
$$

The position relationship in the $3 \mathrm{D}$ space can be expressed as:

$$
Y=\left[\begin{array}{l}
\alpha \\
\beta \\
\gamma
\end{array}\right]
$$

The development speed of urban and rural economic in one cycle can be expressed as:

$\widehat{W}=A \cdot \dot{Y}$

$\widehat{u}=\dot{J}$

$A$ can be expressed:

$$
A=\left[\begin{array}{ccc}
\sin \gamma \sin \beta & 0 & \cos \gamma \\
\cos \gamma \cos \beta & 0 & -\sin \gamma \\
\cos \beta & 1 & 0
\end{array}\right]
$$

Position generalized matrix can be obtained through the generalized coordinates.

$$
B=\left[\begin{array}{ccc}
\cos \alpha \cos \gamma-\sin \alpha \cos \beta \sin \gamma & -\cos \alpha \sin \gamma-\sin \alpha \cos \beta \cos \gamma & \sin \alpha \sin \beta \\
\sin \alpha \cos \gamma-\cos \alpha \cos \beta \sin \gamma & -\sin \alpha \sin \gamma-\cos \alpha \cos \beta \cos \gamma & -\cos \alpha \sin \beta \\
\sin \beta \sin \gamma & \sin \beta \cos \gamma & \cos \beta
\end{array}\right] .
$$

Among them, $n$ hi-tech machinery enterprises labor transfer data can be expressed as:

$$
L=\left[L_{1}, L_{2}, L_{3}, \ldots, L_{n}\right] \text {. }
$$

So the developments speed of urban and rural economic in one cycle can be expressed as:

$$
\Phi p(p, t) \dot{p}=-\Phi p(p, t) \text {. }
$$

$$
\Phi p(p, t) \ddot{p}=-\left(\Phi_{p} \dot{p}\right)_{p} \dot{p}-2 \Phi_{p_{t}} \dot{p}-\Phi t t(p, t) \text {. }
$$

In order to realize the velocity and acceleration algorithm of urban and rural labor transfer negative feedback, this paper uses MATLAB software to program algorithm, and the program is as follows:

count $2=$ length $(\operatorname{coefs} 1)$;

count3=length( $\operatorname{coefs} 2)$;

energy $\left.1=\operatorname{sum}((\operatorname{abs}(\operatorname{coefs} 1)))^{\wedge} 2\right)$;

energy $2=\operatorname{sum}\left((\operatorname{abs}(\operatorname{coefs} 2)) .^{\wedge} 2\right)$;

energy $3=$ energy $1+$ energy 2 ;

for $\mathrm{i}=1$ : count 2

recoefs $1(\mathrm{i})=\operatorname{coefs} 1(\mathrm{i}) /$ energy 3 ;

end 
for $\mathrm{i}=1$ : count 3

recoefs $2(\mathrm{i})=\operatorname{coefs} 2(\mathrm{i}) /$ energy 3 ;

end

\section{Research on the Urban and Rural Labor Transfer for High-tech Machinery Enterprises}

The development of urban and rural ecological economy mainly depends on the mechanical and other high-tech enterprises. In order to verify the effectiveness and reliability of Ranis-Fei 3D space improved algorithm designed in second section, this paper uses the mechanical high-tech enterprise as the research object to study the urban and rural labor force transfer.

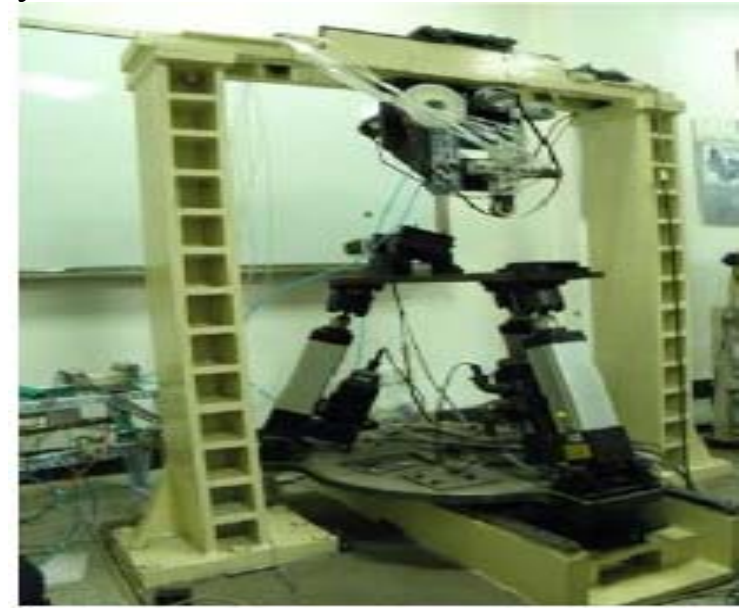

Fig. 2 Automatic machine

As shown in Figure 2, with the increase of mechanical automation level, the township workers lack of technology makes the labor transfer turning [7]. Therefore the Ranis-Fei model is no longer applicable to urban and rural labor transfer of high-tech enterprises and it is more related to the UG, ANSYS and other high-end design simulation software, as shown in Figure 3.

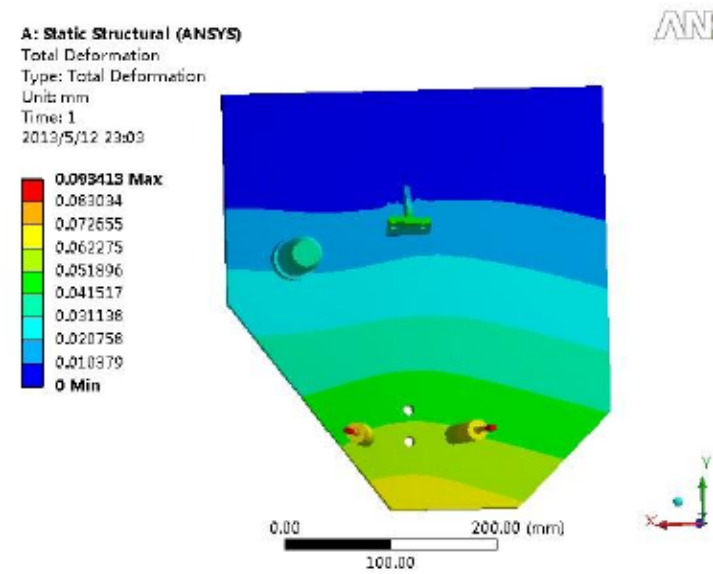

Fig. 3 Mechanical automation simulation

Figure 3 shows the mechanical automation process using ANSYS software. It is convenient to carry out the simulation design of mechanical products using this software, and can develop mechanism processing. The software technology is difficult to be mastered by ordinary township workers, which affects the labor force transfer from the technical level. 


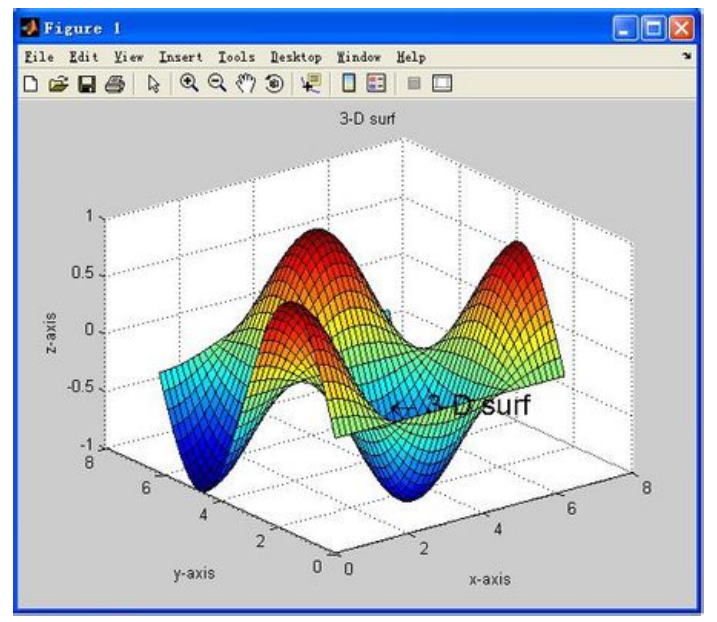

Fig. 4 Data processing of MATLAB labor force transfer

Fig. 4 shows the surface relationship of surplus labor, high-tech talent demand and urban/rural labor force transfer in 3D space using MATLAB simulation [8]. In order to increase the visual of data, this paper does dimension reduction processing on $3 \mathrm{D}$ model; finally the two-dimensional graph is obtained as shown in Figure 5.

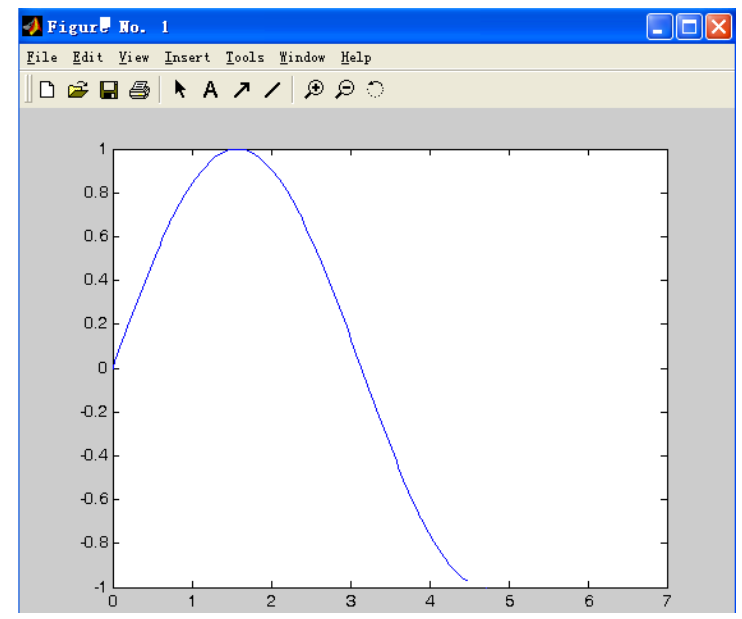

Fig. 5 Labor transfer two-dimensional curve

Figure 5 shows a two-dimensional curve of labor transfer. Through the MATLAB plane curve fitting, the curve of the urban/rural labor changing with time is obtained. From the chart it can be seen, with the change of time, machinery enterprises labor appear negative transfer, which is mainly related with the innovation of mechanical automation technology [9]. With the application of a variety of simulation software, it needs simulation software to design the product before mechanical processing, but such talent has less distribution in township, which results in negative transfer of technical labor

\section{Summary}

Combined with the theory of generalized matrix, this paper uses the labor negative feedback of mechanical high tech enterprise to improve Ranis-Fei model, finally the urban and rural ecological economy development model under the new situation is obtained. In order to verify the effectiveness and the reliability of the model, this paper uses the MATLAB numerical simulation toolbox to program the algorithm, combined with the use of ANSYS software and their influences on labor transfer, through numerical simulation this paper gets the 3D surface relationship and 2D curve of labor transfer, which verifies the labor force negative transfer. Although the simulation verifies the effectiveness of improved Ranis-Fei model on the urban and rural ecological economy development, but its reliability still needs to be further evaluated, so it can provide theoretical basis and technical reference for urban and rural labor transfer under the background of ecological economy.

Fund project: 2013 China National Natural Science Fund Project, "an equitable distribution of value-added benefits of rural tourism in Yunnan Land Mechanism" (G30) 


\section{Acknowledgements}

About the author: Hui-Li (1983-), male, Kunming, Yunnan, Han, Kunming Institute of Social Management School, Lecturer, Master, is mainly engaged in research Dianchi Lake drainage basin, The reform of the Social security system and the Development of Chinese,Frontier Ethnic Development.

\section{References}

[1] S.Z. Gu. The difficulty of new urbanization is urbanization. Chongqing and the world, 2013, 2(3): $12-15$.

[2] X.M. Yan. New agricultural occupation demand. Journal of Hunan University of Science and Technology, 2012, 2(5): 98-101.

[3] J.Y. Gui. Peasants' citizenization under the citizen perspective of equal rights. Journal of Nantong University, 2012, 1(4): 56-59.

[4] Y. Yang. The transfer of labor force, technology induction and its realization conditions: 477 samples. Reform, 2012, 4(7): 23-25.

[5] J.F. Zhang. Chinese rural labor transfer and the empirical study on gap between urban and rural areas an. Guangdong agricultural science, 2013, 2(4): 42-45.

[6] J.X. He. China's rural labor force transfer quantity calculation and future trend prediction. Journal of Henan Normal University, 2013, 2(4): 65-68.

[7] F.Q. Xiao, R.T. Zhong. The professional cooperative management and New Countryside Construction - based on the investigation of rural in Guigang City of Guangxi. Journal of Jishou University (SOCIAL SCIENCE EDITION), 2012, 4(2): 78-80.

[8] F. Cai. How to further transfer rural surplus labor. Journal of Central Party school, 2012, 3(1): $85-88$.

[9] Q.P. Li. Analysis of the large agriculture promoting employment of the rural work force -- based on a political economic perspective. Journal of Hunan University of Science and Technology, 2012, 4(6): 112-115. 